\title{
Comunicação
}

[Communication]

\section{Pesquisa de anticorpos anti-Brucella abortus e anti-Brucella ovis em ovinos no município de Uberlândia, MG}

[Research of Brucella abortus and Brucella ovis antibodies in sheep of Uberlândia county, MG, Brazil]

\author{
S.R.S. Salaberry ${ }^{1}$, L.M. Paulin ${ }^{2}$, R.L. Santana ${ }^{2}$, J.R. Castro ${ }^{1}$, A.M.C. Lima-Ribeiro ${ }^{1}$ \\ ${ }^{1}$ Faculdade de Medicina Veterinária - Universidade Federal de Uberlândia \\ Av. Ceará, s/no , Bloco $2 \mathrm{D}$, sala 33 - Campus Umuarama \\ 38400-902 - Uberlândia, MG \\ ${ }^{2}$ Instituto Biológico - São Paulo, SP
}

\begin{abstract}
A brucelose, uma doença antropozoonótica de distribuição mundial, é responsável por causar problemas sanitários e prejuízos econômicos. $\mathrm{O}$ gênero Brucella é constituído por seis espécies diferentes (Castro et al., 2005), as quais não são específicas de um hospedeiro, mas possuem predileção por determinadas espécies animais, como a Brucella abortus (B. abortus), que infecta preferencialmente bovinos, e a Brucella ovis (B. ovis), que infecta ovinos (Paulin, 2003).
\end{abstract}

As manifestações clínicas mais comuns da brucelose causada pela Brucella abortus nos animais são o aborto e a retenção de placenta nas fêmeas, e essa doença é frequentemente assintomática nos machos. Quando há manifestação clínica no macho, o sintoma mais comum é orquite. A principal fonte de infecção é representada pela vaca, que durante o aborto ou parto elimina grandes quantidades da bactéria, contaminando o meio ambiente (Brasil, 2006).

A brucelose causada pela Brucella ovis é uma infecção subclínica ou clínica que acomete ovinos, sendo caracterizada por epididimite, orquite e aborto. Não é considerada uma zoonose (World..., 2008) e sua principal via de transmissão é a venérea, por meio do sêmen (Estein, 1999).

Diante da importância sanitária e econômica desta infecção, o objetivo deste estudo foi realizar o primeiro inquérito sorológico para Brucella abortus e Brucella ovis em ovinos no município de Uberlândia, situado no Triângulo Mineiro, MG.
Foram colhidas 334 amostras de soro sanguíneo de ovinos oriundos de 12 propriedades localizadas no município de Uberlândia, MG. As amostras foram colhidas, por punção da veia jugular, aleatoriamente, de ovinos aparentemente sadios, de ambos os sexos, com idades e raças variadas. Respeitaram-se as normas do Comitê de Ética da Universidade Federal de Uberlândia na utilização de animais em pesquisa com parecer favorável (Processo 054/09) para a execução do presente trabalho.

O número de amostras por propriedade foi calculado utilizando-se amostragem estratificada proporcional, de acordo com Ayres et al. (2007), e o cálculo da prevalência foi realizado por amostragem aleatória simples, conforme Thrusfield (2004).

Aplicou-se um questionário epidemiológico em cada propriedade, onde foram anotados dados referentes ao sexo, idade e raça, como também fatores relacionados à produção, reprodução e sanidade animal, segundo Thrusfield (2004).

A pesquisa de anticorpos anti-B. abortus foi realizada no Laboratório de Doenças Infectocontagiosas da Universidade Federal de Uberlândia, utilizando-se o teste do Antígeno Acidificado Tamponado (AAT). O antígeno usado consistiu de uma suspensão celular inativada de B. abortus, amostra 1119-3, produzido pelo Instituto de Tecnologia do Paraná. A metodologia utilizada foi a de Carneiro et al. (2005).

Recebido em 17 de março de 2010

Aceito em 14 de abril de 2011

E-mail: sandrasalaberry@yahoo.com.br 
A pesquisa de anticorpos anti- $B$. ovis foi realizada no Laboratório de Doenças Bacterianas da Reprodução do Instituto Biológico de São Paulo, por meio do teste de Fixação de Complemento, de acordo com World... (2008). O antígeno utilizado consistiu de proteínas e lipopolissacarídeos solúveis, extraídos da bactéria $B$. ovis, amostra Reo 198, produzido pelo Instituto de Tecnologia do Paraná. O título de anticorpos foi considerado como a recíproca da maior diluição de soro, apresentando $50 \%$ de fixação do complemento.

Não foram encontrados ovinos reagentes para $B$. abortus no município de Uberlândia, MG. Resultados diferentes foram encontrados por Pinheiro Júnior et al. (2008), que identificaram $2,5 \%$ (9/360) de aglutininas anti-B. abortus em ovinos no estado de Pernambuco. Ocholi et al. (2005) relataram que a infecção por B. abortus em ovinos é rara, embora já tenha sido relatada em alguns países a ocorrência de abortos em ovelhas relacionada a esta bactéria.

Os bovinos contaminam o meio ambiente $\operatorname{com} B$. abortus (Brasil, 2006) e podem ser fonte de infecção para os ovinos, bem como causar problemas reprodutivos nestes animais (Ocholi et al., 2005). Segundo Carneiro et al. (2005), a criação em sistemas semi-extensivos e consorciados com bovinos, caprinos e ovinos favoreceu a ocorrência de $B$. abortus. Das propriedades pesquisadas neste estudo, $75 \%$ (9/12) utilizavam o sistema semi-extensivo, mas apenas $16,7 \%(2 / 12)$ criavam bovinos junto com ovinos, o que pode ter favorecido a não terem sido encontrados ovinos reagentes. Além disso, segundo BRASIL (2009), a brucelose bovina no estado de Minas Gerais apresentou queda na prevalência de animais positivos de $6,7 \% \mathrm{em}$ 1980 para $1 \%$ em 2002, o que pode justificar o resultado obtido neste estudo.

Não houve ovinos reagentes para $B$. ovis no município de Uberlândia, MG. Este resultado foi semelhante ao encontrado por Marinho e Mathias (1996) e Schäfer et al. (1997), que não detectaram ovinos reagentes para $B$. ovis nos estados de São Paulo e Santa Catarina, respectivamente. Em contrapartida, em outros estudos encontraram-se $11,3 \%$ e $8,59 \%$ de anticorpos anti- $B$. ovis nos estados de Rio Grande do Norte e Paraíba (Azevedo et al., 2004; Clementino et al., 2007).
Segundo Silva et al. (2003), a porcentagem de ovinos adultos (acima de um ano de idade) infectados pela $B$. ovis é superior à dos jovens (abaixo de um ano de idade) e, em contrapartida, machos e fêmeas possuem a mesma suscetibilidade à infecção. Neste estudo, a idade dos ovinos pesquisados variou de seis a 11 meses $(18,6 \%)$, um a três anos $(30,2 \%)$ e maiores que três anos $(51,2 \%)$ e, com relação ao sexo, 94,6\% eram fêmeas e $5,4 \%$ machos. Verificou-se, no presente estudo, a colheita de amostras de sangue de categorias variadas e não houve ovinos reagentes para $B$. ovis.

A ovinocultura é uma atividade em expansão na região e, de acordo com o questionário epidemiológico realizado nas 12 propriedades, $58,3 \%$ (7/12) dos criadores de ovinos relataram que compram ovinos em outros municípios da região e 41,7\% (5/12) compram em outros estados do país. As exposições ou leilões agropecuários são locais que aglomeram animais de diferentes origens e favorecem a disseminação de infecções; 25\% (3/12) dos criadores comentaram que levam os ovinos para estes eventos. Verificou-se também que $100 \%$ destes criadores não exigem exames sorológicos para averiguar a sanidade dos animais ao introduzi-los no rebanho. Com relação à quarentena, 58,3\% (7/12) relataram que a realizam ao adquirir novos ovinos.

Gouveia et al. (2009) descreveram que a maioria dos ovinocultores não reconhece a importância da exigência da documentação sanitária e que a compra de ovinos sem a documentação sanitária predispõe o rebanho mineiro a sérios riscos de introdução de agentes infecciosos relevantes. Além disso, afirmaram que o trânsito entre rebanhos e regiões bem como a baixa frequência de quarentenário são considerados importantes componentes na disseminação de doenças.

Assim, embora a brucelose não seja um problema sanitário que atinja o rebanho ovino deste município, deve-se ressaltar a necessidade de adoção de medidas sanitárias para evitar a introdução desta infecção neste município do Triângulo Mineiro, MG.

Palavras-chave: antígeno acidificado tamponado, brucelose, fixação de complemento 


\begin{abstract}
The first epidemiologic inquiry to Brucella abortus (B. abortus) and Brucella ovis (B. ovis) was carried out in sheep from Uberlândia county, MG. A total of 334 blood serum samples of sheep from both sexes and different ages and breeds were collected in 12 farms. An epidemiologic questionnaire was applied for each farm. Tests for B. abortus and B. ovis antibodies were Buffered Acidified Antigen and Complement Fixation, respectively. None of the sheep was reactive to $\mathrm{B}$. abortus and $\mathrm{B}$. ovis; however, the adoption of sanitary measures is important to avoid the introduction of infections caused by these bacteria.
\end{abstract}

Keywords: buffered acidified antigen, brucelosis, complement fixation

\section{REFERÊNCIAS BIBLIOGRÁFICAS}

AYRES, M.; AYRES, JR.M.; AYRES, D.L. et al. Bioestat 5.0. Aplicações estatísticas nas áreas das ciências biomédicas. Belém: Sociedade Mamiaurá, Imprensa Oficial do Estado do Pará, 2007.

AZEVEDO, S.S.; ALVES, C.J.; ALVES, F.A.L. et al. Ocorrência de anticorpos anti-Brucella ovis em ovinos procedentes de quatro municípios do estado do Rio Grande do Norte, Brasil. Agrop. Tec., v.25, p.45-50, 2004.

BRASIL. Ministério da Agricultura, Pecuária e Abastecimento. Programa Nacional de Controle e Erradicação da Brucelose e Tuberculose Animal. 1.ed. Brasilia, 2006, 188p.

BRASIL. Ministério da Agricultura, Pecuária e Abastecimento. Programa Nacional de Controle e Erradicação da Brucelose e Tuberculose. Situação Sanitária Nacional. Brasília-DF, 2009. Disponível em: <http://www.agricultura.gov.br>. Acessado em: 16 nov. 2009.

CASTRO, H.A.; GONZÁLEZ, S.R.; PRAT, M.I. Brucelosis: una revisión práctica. Acta Bioq. Clin. Latin., v.39, p.203-216, 2005.

CARNEIRO, J.; ZACHARIAS, F.; PACHECO, S.T. et al. Investigação da soropositividade para brucelose em rebanhos caprinos produtores de leite para consumo humano. Rev. Bras. de Saúde e Prod. Anim., v.6, p.53-58, 2005.

CLEMENTINO, I.J.; ALVES, C.J.; AZEVEDO, S.S. et al. Inquérito soro-epidemiológico e fatores de risco associados à infecção por Brucella ovis em carneiros deslanados do semiárido da Paraíba. Pesq. Vet. Bras., v.27, p.137-143, 2007.

ESTEIN, S.M. Aspectos inmunológicos em el diagnóstico y control de la epididimitis contagiosa del carnero por Brucella ovis. Arch. Med. Vet., v.31, 1999.
GOUVEIA, A.M.G.; GUIMARÃES, A.S.; HADDAD, J.P.A. et al. Características zoosanitárias da ovinocultura em Minas Gerais, Brasil. In: Associação dos Criadores de Caprinos e Ovinos de Minas Gerais, $2009 . \quad$ Disponível em: <http://www.caprileite.com.br/conteudo.php?id_conte udo88\&id_links=4\&id_sub_links

=28Sitewww.accomig.com.br $>$. Acessado em: 23 ago. 2009.

MARINHO, M.; MATHIAS, L.A. Pesquisa de anticorpos contra Brucella ovis em ovinos do estado de São Paulo. Pesq. Vet. Bras., v.16, p.45-48, 1996.

OCHOLI, R.A.; KWAGA, J.K.P.; AJOGI, I. et al. Abortion due to Brucella abortus in sheep in Nigeria. Rev. Sci. Tech./ Off. Int. Epiz., v.24, p.973-979, 2005.

PAULIN, L.M. Brucelose. Arq. Inst. Biol., v.70, p.239-249, 2003.

PINHEIRO JUNIOR, J.W.; SOUZA, M.M.A.; GUERRA, N.R. et al. Frequência de aglutininas antiBrucella abortus em caprinos e ovinos do sertão do estado de Pernambuco, Brasil. Cien. Anim. Bras., v.9, p.1096-1101, 2008.

SCHÄFER, I.; VAZ, A.; RAMELLA, J. et al. Prevalência de carneiros reagentes à prova de imunodifusão em gel para Brucella ovis no município de Lages-SC. Hora Vet., v.17, p.60-61, 1997.

SILVA, J.B.A.; FEIJÓ, F.M.C.; TEIXEIRA, M.F.S. et al. Prevalência de brucelose ovina causada por Brucella ovis em rebanhos do estado do Rio Grande do Norte, Brasil. Cien. Anim., v.13, p.51-54, 2003.

THRUSFIELD, M. Epidemiologia Veterinária. 2.ed. São Paulo: Roca, 2004, 556p.

WORLD organisation for animal health. Ovine epididymitis (Brucella ovis). In: __. OIE Terrestrial Manual. 2008. Disponível em: <2008http:// www.oie.int/eng/normes/mmanual/2008/pdf/2.07.09_ OVINE_EPID.pdf $>$. Acesso em: 25 jul. 2009 